East African Medical Journal Vol. 85 No. 5 May 2008

WORKLOAD INDICATORS OF STAFFING NEED METHOD IN DETERMINING OPTIMAL STAFFING LEVELS AT MOI TEACHING AND REFERRAL HOSPITAL

P. Musau, MBChB, MMed, P. Nyongesa, BSc, MBA, A. Shikhule, BA, Dip (Human Resources), E. Birech, BA (Govt \& Public Admin), Dip (Humanities), D. Kirui, HND (Epid), Cert (QA), Cert (HSM), M. Njenga, BSN, D. Mbiti, BSc.(Applied stats), A. Bett, BSc. (Env. Health), L. Lagat, B.Com, and K. Kiilu, Dip (IT), Department of Surgery, Moi Teaching and Referral Hospital, P.O. Box 4606-30100, Eldoret, Kenya

Request for reprints to: Dr. P. Musau, Department of Surgery, Moi Teaching and Referral Hospital, P.O. Box 4606-30100, Eldoret, Kenya

\title{
WORKLOAD INDICATORS OF STAFFING NEED METHOD IN DETERMINING OPTIMAL STAFFING LEVELS AT MOI TEACHING AND REFERRAL HOSPITAL
}

\author{
P. MUSAU, P. NYONGESA, A. SHIKHULE, E. BIRECH, D. KIRUI, M. NJENGA, D. MBITI, \\ A. BETT, L. LAGAT and K. KIILU
}

\begin{abstract}
Background: There is an increasing demand for quality healthcare in the face of limited resources. With the health personnel consuming up to three quarters of recurrent budgets, a need arises to ascertain that a workforce for any health facility is the optimal level needed to produce the desired product. Objective: To highlight the experience and findings of an attempt at establishing the optimal staffing levels for a tertiary health institution using the Workload Indicators of Staffing Need (WISN) method popularised by the World Health Organisation (WHO), Geneva, Switzerland.

Design: A descriptive study that captures the activities of a taskforce appointed to establish optimal staffing levels.

Setting: Moi Teaching and Referral Hospital (MTRH), Eldoret, Kenya, a tertiary hospital in the Rift Valley province of Kenya from September 2005 to May 2006.

Main outcome measures: The cadres of workers, working schedules, main activities, time taken to accomplish the activities, available working hours, category and individual allowances, annual workloads from the previous year's statistics and optimal departmental establishment of workers.

Results: There was initial resentment to the exercise because of the notion that it was aimed at retrenching workers. The team was given autonomy by the hospital management to objectively establish the optimal staffing levels. Very few departments were optimally established with the majority either under or over staffed. There were intradepartmental discrepancies in optimal levels of cadres even though many of them had the right number of total workforce.

Conclusion: The WISN method is a very objective way of establishing staffing levels but requires a dedicated team with adequate expertise to make the raw data meaningful for calculations.
\end{abstract}

\section{INTRODUCTION}

In a world faced with a myriad of problems and dwindling resources, the need to optimise utilisation of the available resources is paramount. There is increasing demand for quality healthcare despite constraints ranging from global politics, economics, environment to staff competency and adequacy. In this scenario, a balance has to be struck between what goes into production and the quality of what comes out as the product. 
A rational method of determining the workforce in various health facilities has been desirable for many years. Past methods of using population ratios (numbers of doctors, nurses etc per 100,000 population) and standard staffing schedules (fixed patterns of staffing for health posts, health centres, district hospitals etc in the country) were found to have serious disadvantages, key among them being overstaffing in some facilities and understaffing in others (1). It would be tempting for some institutions to achieve large financial savings by reducing the number of workers but this, unless done properly and objectively, can lead to negative consequences for staff, patients and the organization (2). Staffing levels and skill mix are among the variables that determine length of hospital stay and quality of outcome (3-5). While health managers are hard-pressed to institute measures that yield value for money, impulsive and untested methods may turn out to be counterproductive (6). Cost-cutting measures have an impact on the quality and accessibility of healthcare systems and staff reduction may place patients at risk, including compromise on handling of emergencies (7).

For many years, the staffing of health facilities was based on desired ratio of personnel to the population. This was appropriate as a broad picture but failed to address discrepancies in regional morbidities, health-seeking habits and institutional workloads. Unadjusted staffing ratios underestimate workloads and overstate the staffing levels (8). Facilities in different localities may have different requirements even if of the same bed capacity (9).

The World Health Organisation (WHO) in the 1980s came up with a way of determining appropriate levels of health staff. It takes into account the common activities occupying a given cadre on routine basis, the time it takes to do a given activity, associated activities a cadre does that is not core in the job description, available working time in a year and the annual statistics giving the volume of work (1). This is what is called the Workload Indicators of Staffing Need (WISN).

WISN was popularised by $\mathrm{WHO}$ and pretested in a number of countries including Kenya, Tanzania, Papua New Guinea, Sri Lanka and Turkey but nothing much is in the public domain. It is a method that is objective and given that it is based on data from actual activities should meet little resistance from staff (10).
This paper shares the experience and findings of a task force constituted to establish the optimal staffing levels of the workforce of Moi Teaching and Referral Hospital, a tertiary teaching hospital in Eldoret, Rift Valley province of Kenya.

\section{MATERIALS AND METHODS}

In September 2005, an original team of eight people was appointed by the Director of Moi Teaching and Referral Hospital (MTRH) to:

(i) Determine activity standards in all key departments.

(ii) Establish available annual working time for each staff category.

(iii) Ascertain the volume of work in the departments.

(iv) Determine optimal staffing levels and give recommendations on the basis of the findings.

The eight people were drawn from clinical, planning, administration, human resource and health records and information services sections. Two others were co-opted in the course of the exercise that lasted eight months up to May 2006.

We held daily meetings lasting two and a half hours four days a week up to the time of data analysis when we were given a full week out of our working stations to compile the report.

The first task for the team was to have a good understanding of the terms of reference. This was accomplished in the first two sessions. Thereafter, we formulated a mechanism to assist achieve the set out objectives of:

(i) Establishing the key departments and activity areas where the various cadres of personnel work in the hospital.

(ii) Ascertain the main activities the various cadres are engaged in and the duration to accomplish each of the activities.

(iii) Determining the activity standard; this is the period taken to satisfactorily accomplish the given activity in the setting of the workplace.

(iv) Establishing the working times of the various cadres and whether in shifts, working at night, weekends and public holidays and 
the compensation for time taken in night, weekend and public holiday duties.

(v) Establishing the annual available time for each cadre; subtracting the sum total of public holidays, sick off days and annual leave from the number of days in the year.

(vi) Finding out the activities given cadres do outside their job description and so eating into the working time e.g. guiding students, attending seminars etc. This is referred to as category allowance.

(vii) Finding out the activities some people within cadres engage in apart from their routine duties and category allowance e.g. the nurse in-charge of a ward making duty rotas monthly. This is called individual allowance.

(viii) Establishing the work output for various departments on the basis of activity standards and volume of activity e.g. the turnover of patients in the year, surface area cleaned in the year etc.

Heads of departments and nurse managers in various clinical divisions were asked to collect data from various cadres of workers under them on:

(i) The key activities that occupy them on day to day basis.

(ii) The time it takes to do each of these activities.

(iii) The working schedules, including whether they get day offs after particular days of work.

(iv) Duties they engage in that are not core to their job description e.g. guiding students.

(v) Number of days entitled to have as annual leave.

(vi) Where applicable, activities some of them do outside what is already covered above e.g. in-charges of wards doing duty rotas.

The exercise covered all cadres of workers in the hospital. Where applicable, the WHO set activity standards were used but on the whole, we relied on the activity standards, category and individual allowances originated by the cadres, endorsed by the various heads as true reflection of obtaining working environment and ratified by the members of the task force.
From the provided data, we managed to get:

(a) The activities and activity standards; to make them manageable they had to be grouped into a maximum of four categories to enable effective computations.

(b) The various allowances; category, individual and shift allowances.

(c) The total number of days of various cadres were available to work in a year.

(d) The allowance multiplier given as

$$
\frac{1}{1-\left(\frac{\text { Total } \% \text { category allowance }}{100}\right)}
$$

From the annual statistics availed from Health Records and Information Services Department, we were able to establish the volume of work in the preceding year. Where activities were not directly linked to available statistics e.g. cleaners, security men, laundry and cooking, proxy measures were used e.g. surface area cleaned, key installations, amount of linen required for known activities and number of meals required for patients and others.

It was then possible to calculate the number of workers on the basis of the workload and the WISN formula given the data availed by the heads of departments and nurse managers from the various clinical divisions.

Where pure calculations would not yield sensible figures, managerial judgement was advanced on the basis of concrete references e.g. establishing the number of drivers on basis of available vehicles and work demands. The task force team had expertise from various sections and this was relied on to make decisions when management judgement was required.

\section{RESULTS}

The team was initially seen as a retrenchment tool. It took us a lot of persuasion and openness to get the heads of departments to understand the purpose of the exercise and convey the information to members of staff. Its being a pioneer activity in the region made matters even worse.

Thirty three key departments were determined for the purpose of the exercise of establishing the optimal staffing levels for the hospital. It would be unwieldy to outline all the activities and activity standards for all the cadres of workers in the hospital. Suffice it to say 
that all the activities that routinely occupy the workers were grouped alongside their activity standards into four categories for ease of computation. These constituted the components of the workload that in turn gave us the work output per individual worker.

Table 1 gives us the steps taken to establish optimal staffing levels using the Workload Indicators of Staffing Needs (WISN).

The activity standards varied from cadre to cadre and could range from minutes to hours (as in surgical procedures). The category allowances differed from one group of workers to another depending on how much a given cadre was utilised on activities that did not directly fit into their core duties of teaching, attending seminars, etc. The individual allowance factors were mainly in sectional heads who apart from the cadre activities and allowances, undertook some extra duties like organising time tables and duty allocations. This was usually up to three hours a month. Figure 1 shows some select activity standards and workloads.

The work volumes were dependent on the total available time in a year and the activity standards together with the corresponding category and individual allowances. Each cadre met their work loads on the basis of their numbers and the outcome was the ascertainment as to whether the departments were optimally, under or overstaffed. Figure 2 shows an example of WISN calculation of the optimal number of nurses for paediatric ward based on the annual workload.

After calculations, the optimal levels were compared to numbers currently in place. The departments were broadly grouped into three categories: those optimally staffed, the understaffed and the overstaffed (Table 2).

A peculiar finding was that some departments had figures close to their optimal levels but exhibited major discrepancies within themselves with regard to the cadres. An example is given in Table 3.

These discrepancies remained true even after reviews with heads of affected departments in an effort to ascertain that all that needed to be considered in the calculations was taken into account.

Given the approach - involving the stakeholders throughout - the results, even those unpleasant to the concerned departments, were not contestible and this proved a great asset when the validity and reliability of the report was considered. The management had no doubt that it was a successful effort that would form the basis for the rationalisation of the workforce in an effort to achieve quality health care.

Table 1

The WISN formula for staffing levels

Step 1
A. Establish the activity and its standard.
B. Calculate the category allowance.
C. Calculate the individual allowance.
D. Establish the annual available working time in days.

Step 2
A From available statistics ascertain the workload.
B Divide workload by sum activity standards.
C Multiply quotient in (B) by the multiplier factor derived from category allowance.
D Add individual allowance to (C) above. 
Table 2

Departments and their staffing status

\begin{tabular}{ll}
\hline Status & Departments \\
\hline Optimal & $\begin{array}{l}\text { Senior management, occupational therapy, transport, laboratory, orthopaedic } \\
\text { technology, social work, planning. }\end{array}$ \\
Suboptimal & $\begin{array}{l}\text { Physiotherapy, pharmacy, dental, human resource, internal audit, nursing, } \\
\text { administration, health education and promotion, radiology and imaging, security, } \\
\text { clinical medicine, mortuary. }\end{array}$ \\
Supraoptimal & $\begin{array}{l}\text { Finance, catering, procurement and supplies, telephone services, public health, } \\
\text { maintenance, biomedical engineering, housekeeping, computer services, central } \\
\text { registry, legal, quality assurance, plaster technology }\end{array}$ \\
\hline
\end{tabular}

Table 3

Intradepartmental discrepancies: Laboratory services

\begin{tabular}{|c|c|c|c|}
\hline Cadre & Current in place & Optimal & Difference \\
\hline Microbiology/mycology & 10 & 15 & -5 \\
\hline Biochemistry & 11 & 14 & -3 \\
\hline Parasitology & 03 & 04 & -1 \\
\hline Immunology & 03 & 03 & 0 \\
\hline Haematology & 06 & 10 & -4 \\
\hline Routine Lab & 38 & 34 & 4 \\
\hline Histology & 07 & 06 & 1 \\
\hline Blood services & 19 & 16 & 3 \\
\hline AMPATH & 10 & 05 & 5 \\
\hline Memorial lab & 06 & 07 & -1 \\
\hline Phlebotomists & 19 & 19 & 0 \\
\hline Total & 132 & 133 & -1 \\
\hline
\end{tabular}

\section{Figure 1}

Some select activity standards and workloads

(a) Medical officers in surgical wards: Available for 47 weeks a year. Total patients seen in a year is 4306.

\begin{tabular}{lccc}
\hline Activity engaged in & Hours & Available patients or weeks & Total hours \\
\hline Ward rounds in a week & 20 & 47 & 940 \\
Attending each patient & 0.5 & 4306 & 2153 \\
Clinic reviews in a week & 7.5 & 47 & 352.5 \\
Theatre time per operation & 2 & 2876 & 5726.5 \\
\hline Total annual workload in hours & & & 9526.5 \\
\hline
\end{tabular}


(b) Nurses in paediatric wards: Available 203 days a year, get four night-offs for every three nights worked and total number of patients in the year is 34028 .

\begin{tabular}{llcl}
\hline Activity engaged in & \multicolumn{1}{c}{ Hours } & $(\%)$ & \multicolumn{1}{c}{ Total hours } \\
\hline Admissions and patient monitoring & 1 per patient & 100 & 34028.00 \\
Ward rounds and handing over & 6 per day & - & 1218.00 \\
Administering treatment & 0.33 per patient & 100 & 11342.67 \\
NGT feeding & 1 per patient & 1 & 340.28 \\
Bed-bathing patients & 0.5 per patient & 1 & 170.28 \\
Patient transfers & 0.5 per patient & 5 & 850.70 \\
Bed-making & 0.167 per patient & 100 & 5671.33 \\
Turning patients & 1 per patient & 2 & 680.56 \\
Suction & 0.33 per patient & 2 & 226.85 \\
\hline Total annual workload in hours & & & 54528.50 \\
\hline
\end{tabular}

Figure 2

WISN calculation of optimal number of nurses for paediatric ward

(a) Baseline staff requirement $=\frac{\text { Workload in hours }}{\text { Available working hours }}=\frac{54528.5}{1624}=33.58$

\begin{tabular}{lccc}
\hline Category activity & Hours available hours/Days/weeks & $(\%)$ \\
\hline Teaching students (per day) & 1 & 8 hours/day & 12.5 \\
Team activity coordination per day & 2 & 8 hours/day & 25.0 \\
CME per week & 1 & 40 hours/week & 2.5 \\
\hline Total category allowance calculation & & & 40.0 \\
\hline
\end{tabular}

Multiplier computation: category allowance 40

Allowance multiplier $\quad=\frac{1}{1-04}=\frac{1}{0.6}=1.67$

(b) Intermediate staff requirement = baseline staff requirement multiplied by the allowance multiplier derived from category allowance.

$33.58 \times 1.67=56.06$

\begin{tabular}{lccc}
\hline Individual allowance activity & \multicolumn{2}{c}{ Hours available time } & Fraction \\
\hline Ordering drugs and supplies/day & 1 & 8 hours/day & 0.125 \\
Waiver assessment/day & 1 & 8 hours/day & 0.125 \\
Own ward round to ensure care/day & 1 & 8 hours/day & 0.125 \\
Allocation of staff in the ward/day & 0.5 & 8 hours/day & 0.0625 \\
Making duty rota per month & 16 & 135.3 hours/month & 0.1182 \\
\hline Total individual allowance & & & 0.5557 \\
\hline
\end{tabular}


Shift allowance: Available 203 days a year and get four days off for every three nights worked.

$$
\frac{365}{203} \times \frac{4}{3}=2.397=2.40
$$

Sum total of required nurses: Intermediate staff requirement plus individual allowance plus shift allowance.

$$
56.6+0.56+2.40 \quad=\quad 59.02
$$

(c) Optimal number of nurses $=59$

The pillars of the successful process proved to be:

(i) The composition of the team which was made up of people drawn from the key areas of the hospital cadres and armed with experience that made the exercise a success.

(ii) Commitment of the team members who spared enough time despite their pressing routine duties.

(iii) A free hand from the administration that was genuinely interested in the true findings of the task force.

(iv) Incorporation of the stakeholders into the process to provide reliable data that reflected the true picture on the ground.

Ownership of the report transcended membership of the taskforce and included all members of staff who in one way or another were involved in the generation of the data used. This led to easy adoption of this report by the management. It now forms the basis for staff employment and/or deployment in Moi Teaching and Referral Hospital.

\section{DISCUSSION}

Matters pertaining to staffing norms tend to get emotive due to the growing trend of retrenchment the world over. The managers in health facilities are now expected to prove their worth through prudent utilisation of limited resources. It was, therefore, not a surprise that our efforts at optimal staffing were initially perceived in this context of right-sizing the personnel.

While pressure for better healthcare in the face of limited resources may be mounting, irrational approach to cost-cutting may prove detrimental (7). The objective should be to establish the true picture in terms of workload and the corresponding numbers of the respective cadres. As such, the appointing authority in this task cannot afford to have vested interests in the outcome.

The greatest achievement of the hospital management team in this regard was not the desire to know the optimal staffing levels but having the wisdom not to interfere with the process.

The approach we used in Eldoret has not been documented elsewhere but it has been found in a study that a system based on data from actual practice is unlikely to meet staff resistance (10). This we found to be true in our exercise.

Great attention was paid to the peculiarities of our setup, including infrastructural drawbacks and came up with a report unique to the institution.

Institutional staffing has been found to vary depending on type, regional and economic factors as well as cultural practices of the people utilising it (9). We ensured that what went into the final report reflected the appropriate staffing and skill mix to achieve a consistent quality healthcare irrespective of the time or special days like weekends and public holidays. And the beauty of it all was that it took into consideration all cadres that work in synchrony to produce desirable results for the hospital. Staffing levels and right skill mixes are known to be among the variables determining length of hospital stay and quality of outcome (2-5). Consistent staffing levels and 24 hour access to diagnostics help maintain quality healthcare (11).

Our experience and findings in this study showed that an employment system that is not driven by established rational levels of workers will tend to have discrepancies of cadres within departments. As shown, very few departments were optimal in their establishment, the majority being either under or overstaffed. Unruh and Fottler found that an unadjusted staffing ratio underestimates workloads and overestimates staffing requirements (8).

Moi Teaching and Referral Hospital is probably the only hospital in Kenya that has actively engaged 
itself in an objective staffing norm and policy. Its effort was not aimed at retrenching people but to formulate a way forward where the findings would be utilised both internally and externally, particularly when sourcing funds from the government. Attempts at establishing optimal levels should not be aimed at correcting known staffing anomalies but to enable the institution achieve its targets better (2).

WISN was found to be an objective tool for establishing optimal staffing levels with a potential to cause proper allocation of resources and staffing decisions. Priority areas would be those in which the actual staff is overstretched by the amount of work by more than $10 \%$ (1) on the basis of required staff. By allowing proper utilisation of resources, the WISN method brings about cost effectiveness and improves the quality of service rendered.

But WISN also has its limitations that may impact negatively on its results. It depends on good record keeping. If the information provided is not accurate, the calculated establishment will not be correct. It is also retrospective and may not adequately cater for out of turn events like epidemics, infrastructural changes or influx of refugees not captured in the preceding year.

The example set by MTRH should be emulated by other health institutions, particularly in the countries where World Health Organisation (WHO) pretested the concept of Workload Indicators of Staffing Need (WISN). We found it a very objective method but one that requires a competent team of experts whose experience would go into generating meaningful data.

We recommend the folowing:

(i) MTRH and other related institutions in the region and beyond should feel confident to use the WISNbased optimal staffing levels as the basis of their staff rationalisation, employment or deployment due to its objectivity and reliability of results.

(ii) Regular update of hospital statistics would be required to ascertain reliability of established levels in the years to come.

(iii) The rationalisation of the staffing levels should bear in mind the possible limitations of WISN method and the process of getting the final results. (iv) A widespread use of WISN method is recommended to enable the health care system in Kenya to be objective and productive in its efforts to offer affordable health care.

\section{ACKNOWLEDGEMENTS}

We wish to acknowledge the active role played by departmental heads in MTRH and its director for granting us permission to publish our findings on optimal staffing levels. We are also grateful to Mrs. A. Chepkorir for secretarial services.

\section{REFERENCES}

1. Workload Indicators of Staffing Need (WISN): a manual for implementation. World Health Organisation. Division of Human Resources Development and Capacity Building, Geneva, Switzerland, 1998; 3-4.

2. Garretson, S. Nurse to patient ratios in American health care. Nurse Stand. 2004; 19: 33-37.

3. Schulman, J. Studying determinants of length of hospital stay. J. Perinatol. 2006; 26: 243-245.

4. Dunn, S.V. and Schmitz, K. Nurses' perceptions of patients' requirements for nursing resources. Aust. J. Adv. Nurs. 2005; 22: 33-40.

5. Schubert, M., Schaffert-Witvliet, B. and De Geest, S. Effects of cost saving, strategies and staffing levels on patient and nurse outcomes. A literature review. Pflege. 2005; 18: 320-328.

6. Tabish, S.A. Towards development of professional management in Indian hospitals. J. Manag. Med. 1998; 12: 109-119.

7. Schupfer, G. and Babst, R. Impact and risks of cost cutting programs on the quality of hospital care in Switzerland. Schwez Rundsch Med. Prax. 2005, 94: 1103-1111.

8. Unruh, L.Y. and Fottler, M.D. Patient turnover and nursing staff adequacy. Health Serv. Res. 2006; 41: 599-612.

9. Kim, Y.M., June, K.I. and Cho S.H. Factors related to nurse staffing levels in tertiary and general hospitals. Taehan Kanho Hakhoe Chi. 2005; 35: 1493-1499.

10. Christ, W.R. A method for setting social work staffing standards within a psychiatric hospital. Soc. Work Health Care. 1982; 8: 87-104.

11. Schmulewitz, L., Proudfoot, A. and Bell, D. The impact of weekends on outcome for em ergency patients. Clin. Med. 2005; 5: 621-625. 